\title{
Sağlıklı Yaşam Biçimi Davranışları ile Sosyal Görünüş Kaygısı Arasındaki İlişkinin İncelenmesi
}

\section{Evaluating the Relationship between Healthy Life Style Behaviours and Social Appearance Anxiety}

\author{
Yeliz AKKUŞ $^{\mathrm{a}}$ Rukiye TÜRK ${ }^{\mathrm{b}}$ Arzu AKKUŞ AYDEMİR
}

ÖZ Amaç: Bu çalışma sağlıklı yaşam biçimi davranışları (SYBD) ile sosyal görünüş kaygısı (SGK) arasındaki ilişkinin incelenmesi ve SGK'yı etkileyen faktörleri belirlemek amacıyla yapılmıştır. Gereç ve Yöntem: Bu çalışma ilişkisel tanımlayıcı bir çalışma olup, Kars il merkezinde yaşayan 1143 kişi ile tamamlanmıştır. Verilerin toplanmasında; sosyo-demografik özellikler formu, "Kişisel Bilgi Formu", "Sağlıklı Yaşam Biçimi Davranışları ölçeği-II" ve "Sosyal Görünüş Kaygısı Ölçeği” kullanılmıştır. Bulgular: Yapılan korelasyon analizinde sosyal görünüş kaygısı puanı ile sağlıklı yaşam biçimi davranışları ölçeği alt faktörlerinden sağlık sorumluluğu, fiziksel aktivite, beslenme arasında pozitif yönde; manevi gelişim ve kişilerarası ilişkiler arasında negatif yönde anlamlı ilişki olduğu; stres yönetimi alt faktörü arasında da ilişki olmadığı belirlenmiştir $(\mathrm{p}<0.05)$. Sonuç ve öneriler: Toplumda yaşayan bireyler sağlıklı yaşam biçimi davranışlarını geliştirme yönünde cesaretlendirilmeli ve sosyal görünüş kaygısını azaltmak için uygun sağlık eğitimi uygulamaları geliştirilmelidir.

Anahtar kelimeler: Sağlık, sağlıklı yaşam biçimi davranışları, sosyal görünüş kaygısı

ABSTRACT Objective: This study was conducted to investigate the relationship between healthy lifestyle behaviors (HLSB-II) and social appearance anxiety (SAA) and to determine the factors that affect SAA. Material and Method: This study is a descriptive correlational study and completed with 1143 people living in Kars province center. In gathering the data; socio-demographic characteristics form, "Personal Information Form", "Healthy Life Style Behaviors Scale-II" and "Social Appearance Anxiety Scale" were used. Findings: In the analysis of the correlation, there is a positive correlation between social appearance anxiety score with healthy lifestyle behaviors scale total score and subfactor of this scale, health responsibility, physical activity, nutrition; there is a significant negative correlation between spiritual development and interpersonal relationships; there is not any correlation at stress management subfactor $(\mathrm{p}<0.05)$. Conclusions and recommendations: Individuals living in the community should be encouraged to develop healthy lifestyle behaviors and appropriate health education practices should be developed to reduce social appearance anxiety.

Keywords: Health, healthy life style behaviours, social appearance anxiety

\section{Giriş}

Sağlıklı yaşam biçimi davranışları bireyin sağlıklı bir yaşam ve hastalıklardan korunmak için uyguladığı davranışların tamamı olarak tanımlanmaktadır (1). Sağlıklı yaşam davranışları bir yaşam şekli olup birey bu davranışları kazanabilirse, sağlıklı olma halini sürdürebilir, sağlık durumunu daha iyi

bir seviyeye getirebilir, yaşam kalitesini yükseltir ve anksiyete ile kolaylıkla baş edebilir. Bu nedenle 2030'da Küresel Sağlıklı Bireyler Programı sağlıklı yaşam biçimi davranışlarını teşvik etmeyi ve toplumun, insanların sağlığını geliştirmek için sosyal ve fiziksel olarak sağlıklı çevre oluşturmayı

Geliș Tarihi/Received:01-06-2018 / Kabul Tarihi/Accepted:17-12-2018

aProf. Dr., Kafkas Üniversitesi Sağlık Bilimleri Fakültesi, İç Hastalıkları Hemşireliği ABD, Kars, yelizakkus@gmail.com, ORCID: 0000-0002-9321-2357

bDr. Öğr. Üyesi Kafkas Üniversitesi Sağlık Bilimleri Fakültesi, Doğum ve Kadın Sağlı̆̆ı Hemşireliği ABD, Kars, rahsantur@gmail.com, ORCID: 0000-0002-1424-1564

'Doktora Öğrencisi, Ankara Üniversitesi Eğitim Bilimleri Enstitüsü, Hayat Boyu Öğrenme ve Yetişkin Eğitimi ABD, Ankara, arzu12tr@ hotmail.com, ORCID: 0000-0001-8082-7996

Sorumlu yazar/ Correspondence: Prof. Dr. Yeliz Akkuş, Kafkas Üniversitesi Sağlık Bilimleri Fakültesi, yelizakkus@gmail.com

Atıf: Akkuş Y, Türk R, Akkuş Aydemir A. Sağlıklı yaşam biçimi davranışları ile sosyal görünüş kaygısı arasındaki ilişkinin incelenmesi. Sağlık Bilimleri ve Meslekleri Dergisi 2019;6(1):120-126.

Citation: Akkuş Y, Türk R, Akkuş Aydemir A. Evaluating the relationship between healthy life style behaviours and social appearance anxiety.Journal of Health Science and Profession 2019;6(1):120-126 
amaçlamıştır (2).

Günümüzde teknoloji çok hızlı gelişmiş, bu hızlı gelişim toplumun ve bireyin sağlık ve güzellik algısını da etkilemiştir. Moda, kozmetik ve tıp bilimi toplumu; bireyleri belli bir formun güzel olduğuna inandırmış ve bu formun dışında olan bireylerin toplum tarafindan dışlanabileceğini empoze etmeye başlamıştır (3). Bu nedenle her yaşta insanda özellikle de genç nesilde başkalarına nasıl göründükleri fikri önem kazanmış ve sosyal görünüş kaygısının ortaya çıkmasına neden olmuştur (4). Sosyal anksiyetenin bir çeşidi olarak belirtilen sosyal görünüş kaygısı (SGK), insanların fiziksel görünüşlerinin diğer insanlar tarafından değerlendirilirken yaşadığ 1 gerginlik ve kaygı olarak tanımlanmaktadır (5). Sosyal görünüş kaygisının, bireylerin mesleki, akademik ve sosyal yaşam üzerinde de olumsuz etkileri vardır (6). Ayrica SGK bireylerde beden memnuniyetsizliğine de neden olabilir (7). Beslenme alışkanlığ 1 , kendini gerçekleştirme, sağlık sorumluluğu, egzersiz alışkanlığı, kişilerarası destek ve stres yönetimine yönelik yapılan değerlendirmelerin bir bileşkesi olarak ortaya konulan Sağlıklı Yaşam Biçimi Davranışlarının (SYBD) kazanılması anksiyete üzerine olumlu etkisi olduğu bilinmektedir $(8,9)$. Literatür incelemesinde genellikle sosyal görünüş kaygısının anksiyete, depresyon ve benlik saygısı gibi kavramlarla ilişkisinin incelendiği, ancak SYBD ile ilişkisinin incelenmediği belirlenmiştir. $\mathrm{Bu}$ nedenle bu çalışma Kars'ta en az lise mezunu olan bireylerde SYBD ile SGK arasındaki ilişkiyi belirlemek amacıyla yapılmıştır.

\section{Yöntem}

\section{Araştırmanın Modeli}

$\mathrm{Bu}$ çalışma ilişkisel tanımlayıcı tipte bir çalışmadır.

\section{Araştırmanın Evren ve Örneklemi}

Araştırmanın evrenini Kars'ta yaşayan en az lise mezunu, 18 yaş üstü bireyler oluşturmuştur. 2016 y1lı Türkiye İstatistik Kurumu verilerine göre Kars ilinde 15 yaş üstü 37.472 lise mezunu bulunmaktadır. Kars il merkezinde 18 yaş üstü lise mezunu birey sayısına ilişkin veriye ulaşılamamıştır. Araştırma genel tarama modelinde yapılmıştır. Genel tarama modeli, kalabalık bir evrende, evrenin tamamı ya da ondan alınacak bir grup üzerinde bir yargıya varmak için yapılan taramalardır. ${ }^{10}$ Bireyler kolayda örnekleme yöntemi ile seçilmiştir ve çalışma katılmaya istekli
1143 kişi (evren sayısına ulaşılamadığından) ile tamamlanmıştır.

\section{Veri toplama araçları}

Araştırmada veri toplama araçları olarak; sosyodemografik özellikler formu, "Kişisel Bilgi Formu", "Sağlıklı Yaşam Biçimi Davranışları ölçeği-II" ve "Sosyal Görünüş Kaygısı Ölçeği" kullanılmıştır.

Sağlıklı Yaşam Biçimi Davranışları Ölçeği-II (SYBDÖ-II): 52 madde ve altı boyuttan oluşan ölçek, Walker ve ark (11), tarafindan 1987 yılında geliştirilmiş, SYBDÖ-II'nin Türkçe geçerlilik ve güvenirliği Bahar ve ark (12) tarafindan 2008 yılında yapılmıştır. Alt boyutlardan alınabilecek en düşük ve en yüksek puanlar sirasıyla, manevi gelişim=9-36, sağlık sorumluluğu=9-36, beslenme =9-36, fiziksel aktivite $=8-32, \quad$ kişileraras 1 ilişkiler $=9-36$ ve stres yönetimi $=8-32$ şeklindedir. SYBDÖ alınan puanın artması olumlu olarak değerlendirilmektedir. Ölçeğin genel puanı sağlıklı yaşam biçimi davranışları puanını vermektedir. Ölçeğin tüm maddeleri olumludur. Derecelendirme 4'lü likert şeklindedir. Hiçbir zaman $=1$, bazen=2, sik $s 1 k=3$, düzenli olarak=4 olarak kabul edilmektedir. Ölçeğin tamamı için en düşük puan 52 , en yüksek puan $208^{\prime}$ dir.

Sosyal Görünüş Kaygısı Ölçeği (SGKÖ): Türkçe geçerlik güvenirlik çalışması Doğan (2010) tarafindan yapılan ölçek, bireylerin Sosyal Görünüş Kaygılarını ölçmek amacıyla Hart ve arkadaşları (2008) tarafından geliştirilmiştir $(5,13)$. Birinci maddesi tersten kodlanan ölçek, 16 maddeden oluşmaktadır. SGKÖ, 5' li Likert tipinde Hiç Uygun Değil=1, Tamamen Uygun $=5$ şeklinde bir cevaplama anahtarına sahiptir. Tek boyutlu olarak sosyal görünüş kaygısını ölçen SGKÖ'den alınan yüksek puanlar görünüş kaygısının yüksek olduğuna işaret etmektedir.

\section{Verilerin Değerlendirilmesi}

Veriler SPSS (Statistical Package for Social Sciences) for Windows 21.0 programı kullanılarak analiz edilmiştir. Ayrıca tüm veriler üzerinde homojenlik (Levene) ve normallik (KolmogorovSimirnov) test işlemleri gerçekleştirilmiş ve verilerin normal dağılım göstermediği belirlenmiştir. Verileri değerlendirilirken sayı, yüzde, ortalama, 
standart sapma, man-whitney U testi, kruskal wallis testi ve spearman korelasyon analizi kullanılmıştır.

\section{Araştırmanın Etik Yönü}

Veri toplama araçları, etik kurul izni (Kafkas Üniversitesi-80576354-050-99183) alındıktan sonra, araştırmaya katılmayı kabul eden bireylerin yazılı onamları alınmış ve yüz yüze görüşme yöntemi kullanılarak uygulanmıştır.

\section{Bulgular}

Çalışmaya katılan bireylerin yaş ortalaması 22,06 $\pm 2,49$ (Min:18, Max: 30)'dur. SGKÖ puan ortalaması $33,96 \pm 13,88$ olup, SGKÖ puan ortalaması erkeklerde, ön-lisans mezunlarında, bekârlarda, gelir gideri karşılamayanlarda ve sigara İçenlerde daha yüksektir ve fark istatistiksel olarak önemlidir $(\mathrm{p}<0.05) \quad($ Tablo 1). SYBDÖ toplam ölçek puan ortalaması $128,22 \pm 2,00$ olup

Tablo 1. Bazı sosyo-demografik özelliklere göre ölçek puanlarının karşılaştırılması

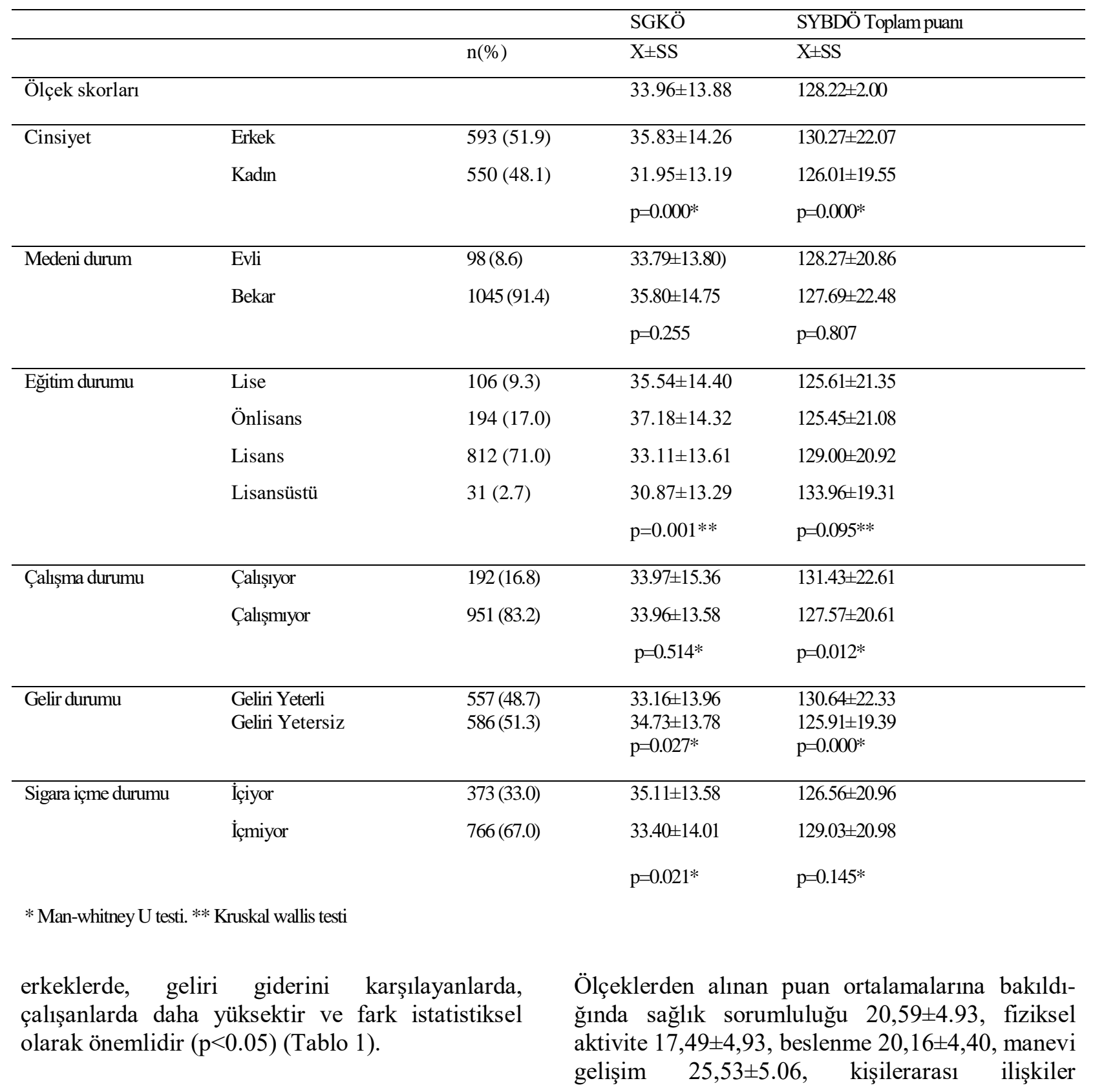


$24,64 \pm 5,05$ ve stres yönetimi $128,22 \pm 21,00$ 'dır. Yapılan korelasyon analizinde SGKÖ puanı ile SYBDÖ alt boyutlarından; sağlık sorumluluğu, fiziksel aktivite, beslenme arasında zayıf pozitif yönde; manevi gelişim ve kişilerarası ilişkiler arasında zayıf negatif yönde anlamlı ilişki olduğu; SYBDÖ toplam puanı ve stres yönetimi alt faktörü arasında da ilişki olmadığı belirlenmiştir (Tablo 2).

Tablo 2. Bazı Değişkenlerle SGKÖ Arasındaki İlişkinin Belirlenmesi

\begin{tabular}{|c|c|c|c|c|c|c|c|c|c|}
\hline & Yaş & BMI & $\begin{array}{l}\text { Sağlık } \\
\text { sorumluluğu }\end{array}$ & $\begin{array}{l}\text { Fiziksel } \\
\text { aktivite }\end{array}$ & Beslenme & $\begin{array}{l}\text { Manevi } \\
\text { Gelişim }\end{array}$ & $\begin{array}{l}\text { Kişilerara } \\
\text { sı ilişkiler }\end{array}$ & $\begin{array}{l}\text { Stres } \\
\text { yönetimi }\end{array}$ & $\begin{array}{l}\text { Toplam } \\
\text { SYBDÖ }\end{array}$ \\
\hline BMI & $\begin{array}{l}\text { r:0.23** } \\
\text { p:0.000 }\end{array}$ & - & & & & & & & \\
\hline $\begin{array}{l}\text { Sağlık } \\
\text { sorumluluğu }\end{array}$ & $\begin{array}{l}\text { r:0.10** } \\
\text { p:0.000 }\end{array}$ & $\begin{array}{l}\text { r:0.94** } \\
\text { p:0.002 }\end{array}$ & - & & & & & & \\
\hline $\begin{array}{l}\text { Fiziksel } \\
\text { aktivite }\end{array}$ & $\begin{array}{l}\text { r:0.09** } \\
\text { p:0.002 }\end{array}$ & $\begin{array}{l}\text { r:0.13** } \\
\text { p:0.000 }\end{array}$ & $\begin{array}{l}\text { r:0.56** } \\
\text { p:0.000 }\end{array}$ & - & & & & & \\
\hline Beslenme & $\begin{array}{l}\mathrm{r}: 0.08 * * \\
\mathbf{p : 0 . 0 0 5}\end{array}$ & $\begin{array}{l}\text { r:0.08** } \\
\text { p:0.004 }\end{array}$ & $\begin{array}{l}\mathrm{r}: 0.58 * * \\
\mathbf{p : 0 . 0 0 0}\end{array}$ & $\begin{array}{l}\text { r:0.52** } \\
\text { p:0.000 }\end{array}$ & - & & & & \\
\hline $\begin{array}{l}\text { Manevi } \\
\text { Gelişim }\end{array}$ & $\begin{array}{l}\mathrm{r}: 0.00^{* *} \\
\mathrm{p}: 0.91\end{array}$ & $\begin{array}{l}\mathrm{r}: 0.03 \\
\mathrm{p}: 0.298\end{array}$ & $\begin{array}{l}\text { r: } 0.29 * * \\
\text { p:0.000 }\end{array}$ & $\begin{array}{l}\mathrm{r}: 0.22 * * \\
\mathbf{p : 0 . 0 0 0}\end{array}$ & $\begin{array}{l}\text { r:0.27** } \\
\text { p:0.000 }\end{array}$ & - & & & \\
\hline $\begin{array}{l}\text { Kişilerarası } \\
\text { ilişkiler }\end{array}$ & $\begin{array}{l}\mathrm{r}: 0.00 \\
0.89\end{array}$ & $\begin{array}{l}\mathrm{r}: 0.02 \\
0.425\end{array}$ & $\begin{array}{l}\mathrm{r}: 0.35^{* *} \\
\mathbf{0 . 0 0 0}\end{array}$ & $\begin{array}{l}\mathrm{r}: 0.19^{* * *} \\
\mathbf{0 . 0 0 0}\end{array}$ & $\begin{array}{l}\mathrm{r}: 0.30^{* *} \\
\mathbf{0 . 0 0 0}\end{array}$ & $\begin{array}{l}\text { r:0.69** } \\
\mathbf{0 . 0 0 0}\end{array}$ & - & & \\
\hline Stres yönetimi & $\begin{array}{l}\text { r:0.05 } \\
\text { p:0.086 }\end{array}$ & $\begin{array}{l}\mathrm{r}: 0.05 \\
\mathrm{p}: 0.094\end{array}$ & $\begin{array}{l}\mathrm{r}: 0.52^{* * *} \\
\mathbf{p : 0 . 0 0 0}\end{array}$ & $\begin{array}{l}\text { r:0.50** } \\
\text { p:0.000 }\end{array}$ & $\begin{array}{l}\text { r:0.42** } \\
\text { p:0.000 }\end{array}$ & $\begin{array}{l}\mathrm{r}: 0.51 * * \\
\mathbf{p : 0 . 0 0 0}\end{array}$ & $\begin{array}{l}\text { r:0.39** } \\
\text { p:0.000 }\end{array}$ & - & \\
\hline $\begin{array}{l}\text { Toplam } \\
\text { SYBDÖ }\end{array}$ & $\begin{array}{l}\text { r:9.70* } \\
\text { p:0.017 }\end{array}$ & $\begin{array}{l}\text { r:0.09** } \\
\text { p:0.002 }\end{array}$ & $\begin{array}{l}\mathrm{r}: 0.75^{* *} \\
\mathbf{p : 0 . 0 0 0}\end{array}$ & $\begin{array}{l}\text { r:0.68** } \\
\text { p:0.000 }\end{array}$ & $\begin{array}{l}\text { r:0.69** } \\
\text { p:0.000 }\end{array}$ & $\begin{array}{l}\text { r:0.68** } \\
\text { p:0.000 }\end{array}$ & $\begin{array}{l}\text { r:0.67** } \\
\text { p:0.000 }\end{array}$ & $\begin{array}{l}\mathrm{r}: 0.756^{* *} \\
\mathbf{p : 0 . 0 0 0}\end{array}$ & - \\
\hline SGKÖ & $\begin{array}{l}\mathrm{r}: 0.03 \\
\mathrm{p}: 0.315\end{array}$ & $\begin{array}{l}\mathrm{r}: 0.05 \\
\mathrm{p}: 0.06\end{array}$ & $\begin{array}{l}\mathrm{r}: 0.13^{* *} \\
\mathbf{p : 0 . 0 0}\end{array}$ & $\begin{array}{l}\mathrm{r}: 0.13 * * \\
\mathbf{p : 0 . 0 0 0}\end{array}$ & $\begin{array}{l}\mathrm{r}: 0.16^{* *} \\
\mathbf{p : 0 . 0 0 0}\end{array}$ & $\begin{array}{l}\text { r:-0.27** } \\
\text { p:0.000 }\end{array}$ & $\begin{array}{l}\mathrm{r}:-0.18 * * \\
\text { p:0.000 }\end{array}$ & $\begin{array}{l}\mathrm{r}: 0.22 \\
\mathrm{p}: 0.452\end{array}$ & $\begin{array}{l}\text { r:-0.00 } \\
\text { p:0.896 }\end{array}$ \\
\hline
\end{tabular}

$* \mathbf{p}<0.05 * * \mathbf{p}<0.01$

\section{Tartışma}

Bizim bildiğimiz kadarıyla Kars'ta yaşayan bireylerde SYBD ile SGK arasındaki ilişkiyi belirlemeye yönelik ilk çalışmadır. Bu nedenle bu çalışmanın önemli olduğu düşünülmektedir.

$\mathrm{Bu}$ çalışmada SGKÖ puan ortalaması $33.96 \pm 13.88$ olarak saptanmıştır (Tablo 1). Yapılan çalışmalarda SGKÖ puanına ilişkin farklı sonuçlar elde edilmiştir. Sırasıyla SGKÖ puan ortalaması akne vulgarisli bireylerde $33.76 \pm 12.94$ ve ev kadınlarında $38.8 \pm 15.5$ olarak saptanmıştır (1416). Üniversite öğrencileri ile yapılan çalışmalara bakıldığında SGKÖ puan ortalamasının 31.5334.11 arasında değiştiği görülmektedir (17-19). Bu çalışmanın sonucu literatürle uyumlu olup çalışmamıza katılan bireylerin orta düzeyde SGK yaşadığı söylenebilir.

$\mathrm{Bu}$ çalışmada da erkeklerde SGKÖ puan ortalaması daha yüksek bulunmuştur (Tablo 1).
Literatür incelemesinde cinsiyetin SGKÖ puan ortalaması üzerine etkisine yönelik çalışmalara bakıldığında erkeklerde $(13,17,18)$ ya da kadınlarda yüksek olduğuna ilişkin (20) çalışmaların yanı sıra cinsiyetin etkilemediğine ilişkin çalışmalar da bulunmaktadır (20-221). Gerçekte erkeklerin SGKÖ puanının kadınlara göre daha düşük olması beklenmektedir. Ancak toplumumuzda erkeklerin konumları gereği toplumla daha fazla içli dışlı olmaları bu sonucu ortaya çıkarmış olabilir. Ülkü (2017) çalışmasında medeni duruma göre SGKÖ puanında fark olmadığını belirtmiştir (21). Kılıç (2015) erkek ya da kız arkadaşı olmayanlarda SGKÖ puanının daha yüksek oldu-ğunu belirtmiştir (17). Ayrıca bu çalışmada SGKÖ puanı bekarlarda daha yüksektir (Tablo 1), bu sonuç bekarlarda beğenilmeme korkusu nedeniyle olabilir.

$\mathrm{Bu}$ çalışmada geliri giderini karşılamayan- 
larda SGKÖ puan ortalamasının anlamlı şekilde yüksek olduğu görülmüştür (Tablo 1). Yapılan iki çalışmada bireylerin çalışma durumuna ve aylık harcanan para miktarına göre SGKÖ puan ortalaması arasında fark olmadığ1 belirlenmiş-tir $(17,21)$. Özcan ve ark. da (2013) gelir düzeyi ile SGKÖ arasında negatif yönde ilişki olduğunu belirtmiş, gelir düzeyi arttıkça SGKÖ puanının düştüğünü saptamıştır (23). Bireyin gelirinin fazla olmas1, istediği aktiviteleri yapabilmesine, daha fazla insanla karşılaşmasına ve sosyal ortamda daha fazla bulunmasina neden olabilir ve bu nedenle SGK puanı geliri giderini karşılamayanlarda düşük olabilir.

Bu çalışmada, SGKÖ puanı ile SYBDÖ toplam puanı arasında ilişki olmadığı saptanmıştır (Tablo 2). Literatür incelemesinde SGKÖ ile SYBDÖ arasındaki ilişkiye yönelik çalışmaların sınırlı olduğu görülmektedir. Bununla birlikte bu çalışmaya benzer şekilde yapılan iki çalışmada da ev kadınlarında ve öğrencilerde SGKÖ ile SYBDÖ arasında ilişki olmadığını belirlenmiştir $(16,19)$.

$\mathrm{Bu}$ çalışmanın sonuçlarına göre de SYBDÖ’nin sağlık sorumluluğu alt boyutu puanı arttıkça SGKÖ puanı artmaktadır (Tablo 2). Literatür incelemesinde yapılan çalışmalarda SGKÖ ile sağlik sorumluluğu arasında ilişki olmadığ belirlenmiştir $(16,19)$. Sağlık sorumluluğu; bireyin sağlı̆̆ını korumak ve hastalıkları önlemek için kendi tutum ve davranışlarını değiştirmesi anlamına gelmektedir. Sağlık sorumluluğu aynı zamanda, bireyin kendi sağlı̆̆ına ne düzeyde katıldığını gösteren bir belirleyicidir (12). Günümüzde sağlıklı olmanın önemli bir ölçütü olan dış görünüşün ön planda tutulması bu çalışmada bireylerin sağlık sorumluluğunu artırmış olabilir.

Çalışmamızda SYBDÖ'nin fiziksel aktivite alt boyutu puanı arttıkça SGKÖ puanı artmaktadır. Benzer şekilde Alemdağ (2013) fiziksel aktiviteye katılım durumunun SGKÖ'nün anlamlı bir yordayıcısı olduğunu belirtmiştir (18). Yapılan diğer iki çalışmada fiziksel aktivite ve SGKÖ puanı arasında anlamlı bir ilişki olmadığı saptanmıştır $(16,19)$. Fiziksel aktivite kol ve bacak hareketleri, baş ve gövde hareketleri gibi temel vücut hareketleri olmasının yanında; çömelme kalkma, yürüme, koşma, sıçrama, yüzme bisiklete binme gibi aktiviteleri kapsar. Ayrıca çeşitli spor dalları, dans, egzersiz, oyun ve gün içerisindeki aktiviteler fiziksel aktivite olarak kabul edilebilir. ${ }^{25}$ Fiziksel aktivite birey tarafindan aktivitelerin ne düzeyde yapıldığını göstermektedir. Fiziksel aktivite iyi bir görünüşe sahip olmak ve sağlıklı yaşam biçiminin sürdürülmesi için önemli bir anahtardır. $\mathrm{Bu}$ çalışmanın sonucu bu bulguyu destekler niteliktedir.

Bu çalışmada, SYBDÖ'nin beslenme alt boyutu puanı arttıkça SGKÖ puanı artmaktadır (Tablo 2). Yapılan iki çalışmada da SYBDÖ'nin beslenme alt boyutu ile SGK arasında ilişki olmadığı saptanmıştır $(16,19)$. Bununla birlikte literatür incelemesinde beslenme davranışı, obezite, aşırı yeme, bulimia nevroza gibi beslenme sorunları ile SGK arasındaki ilişkiye yönelik çalışmaların sıklıkla yapıldığ 1 görülmektedir (2628). Kılıç ve Karakuş (2016) üniversite öğrencileri ile yapmış olduğu çalışmada da kilosundan hiç memnun olmayanlarda SGKÖ puan ortalamasının daha yüksek olduğunu belirtmiştir (17). Kilosundan memnun olmayanların beden algisının ve özgüvenin daha düşük olduğu ve depresyona daha fazla yatkın oldukları bilinmektedir (18).

Bu çalışmada SYBDÖ'nin manevi gelişim alt boyutu puanı arttıkça SGKÖ puanı azalmaktadır (Tablo 1). Şanlıer ve ark. (2017) çalışmasında da benzer sonuç elde edilmiştir (19). Maneviyat terimi, mana için bir arayış, bir dine bağlılık, enerji ve temel güvenin dengelenmesi olarak tanımlanır. ${ }^{29}$ Maneviyat insan olmanın bir gereğidir. Maneviyat kişinin sosyalleşmesini, anksiyetenin azalmasını ve teslimiyet duygusunun sağlanması, kendilerini olduğu gibi kabullenmelerini sağlayarak sosyal görünüş kaygısını azaltabilir.

Çalışmamızın sonuçlarına göre SYBDÖ’nin kişilerarası ilişkiler alt boyutu puanı arttıkça SGKÖ puanı azalmaktadır (Tablo 2). Şanlier ve ark. (2017) çalışmasında da benzer sonuç elde edilmiştir (19). Bununla birlikte Pehlivan ve ark. (2017) çalışmasında SYBDÖ’nin kişilerarası ilişkiler alt boyutu puanı ile SGKÖ puanı arasında ilişki saptanamamıştır (16). Kişilerarası ilişkiler bireyin yakın çevresinde bulunan kişilerle olan iletişimini ve süreklilik düzeyini belirlemektedir. $\mathrm{Bu}$ sonuç SGK olan bireylerin kişilerarası ilişkiler kurmaktan kaçındığını ya da sorun yaşadığını düşündürmektedir.

\section{Sonuç ve Öneriler}

Bu çalışmada, SGKÖ puanı ile SYBDÖ toplam puanı arasında ilişki olmadığı bununla birlikte SYBDÖ alt boyutlarından sağlık sorumluluğu, fiziksel aktivite, beslenme arasında zayıf pozitif 
yönde ilişki olduğu belirlenmiştir. Bu sonuca göre fiziksel aktivite ve beslenme eğitiminin anksiyeteye neden olmayacak şekilde planlanması, SYBD geliştirilmesine yönelik yaşam tarzı değişiklikleri için eğitim ve danışmanlık planlanması önerilmiştir. Ayrıca çalışmanın düşük eğitime sahip bireylerde, kronik hastalığa sahip bireylerde ve ileri yaştaki bireylerde yapılması önerilmiştir.

\section{Araştırmanın Sınırlılıkları}

Çalışmanın planlanması aşamasında 18 yaş üstü tüm yaş gruplarına ulaşılmak istenmiştir. Bununla birlikte diğer yaş gruplarından katılımın az olması nedeniyle çalışma 18-30 yaş arası bireylerle sinırlidir.

\section{Çıkar Çatışması Beyanı}

Yazarlar çıkar çatışması olmadığını bildirmişlerdir.

\section{Finansal Destek}

$\mathrm{Bu}$ çalışma için herhangi bir finansal destek alınmamıștır.

\section{Kaynaklar}

1- Karaca T, Özkan SA. Örneklemini hemşirelik öğrencileri ve hemşirelerin oluşturduğu sağlıklı yaşam biçimi davranışları ölçeği kullanılarak yapılan çalışmaların incelemesi: Bir literatür çalışması. JHS 201613 (2): 35883601. doi:10.14687/jhs.v13i2.3869.

2- Secretary's Advisory Committee on National Health Promotion and Disease Prevention Objectives for 2030: Recommendations for an Approach to Healthy People 2030 https://www.healthypeople.gov/sites/default/fi les/Full\%20Committee\%20Report\%20to\%20 Secretary\%205-9-2017 0.pdf [accessed 05.10.2017].

3- Ahıska, M. ve Yenal, Z. Aradığınız Kişiye Şu An Ulaşlamıyor: Türkiye'de Hayat Tarzı Temsilleri, 1980-2005. 2006, İstanbul: Ofset Yayınevi.

4- Trekels, J. \& Eggermont, S. Linking Magazine Exposure to Social Appearance Anxiety: The Role of Appearance Norms in Early Adolescence. Journal of Research on Adolescence. 2017 27(4), 736-751

5- Hart TA, Flora DB, Palyo SA, Fresco DM, Holle C, Heimberg RC. Development and examination of the social appearance anxiety scale. Assessment 2008 15, 48-59.
6- Dindar M \& Akbulut Y. Role of self-efficacy and social appearance anxiety on gaming motivations of MMOFPS players. Computers \& Education 2015 81: 26-34.

7- Claes L, Hart TA, Smits D, Van den Eynde F, Mueller A, et al. Validation of the social appearance anxiety scale in female eating disorder patients. Eur Eat Disord Rev. 2012 20(5):406-9.

8- Scott KM, Bruffaerts R, Simon GE, Alonso J, Angermeyer M, de Girolamo G, et al. Obesity and mental disorders in the general population: results from the world mental health surveys. Int J Obes (Lond). 2008 32(1):192-200.

9- $\mathrm{Xu} \mathrm{Q}$, Anderson D, Courtney M. A longitudinal study of the relationship between lifestyle and mental health among midlife and older women in Australia: findings from the healthy aging of women study. Health Care for Women International. 2010 31(12):10821096.

10- Karasar N. Bilimsel Araştırma Yöntemi, Bilim Kitap Kırtasiye, Ankara, 1986.

11- Walker SN, Sechrist KR, Pender NJ. The Health Promoting Lifestyle Profile Development and Psychometric Characteristics. Nursing Research, 1987 36(2):76-80.

12- Bahar Z, Beșer A, Gördes N, Ersin F, Kısal A. Sağlıklı Yaşam Biçimi Davranışları Ölçeğinin Geçerlik ve Güvenirlik Çalışması. Cumhuriyet Üniversitesi Hemşirelik Yüksekokulu Dergisi, 200812 (1): 1-12.

13- Doğan T. Sosyal Görünüş Kaygısı Ölçeği’nin (SGKÖ) Türkçe Uyarlaması: Geçerlik ve Güvenirlik Çalışması. Hacettepe Üniversitesi Eğitim Fakültesi Dergisi, 2010; 39: 151-159.

14- Erdemir AV, Bağc1 SI, İnan EY, Turan E. Evaluation of the Social Appearance Anxiety and Quality of Life in Patients with Acne Vulgaris.İstanbul Med J.2013 14(1):

15- Yılmaz N. Obez Bireylerde Benlik Saygisı, Sosyal Görünüş Kaygısı Ve Vücut Algısı. Dokuz Eylül Üniversitesi Tip Fakültesi Aile Hekimliği Anabilim Dalı Uzmanlık Tezi . İzmir, 2015.

16- Pehlivan Z, Ada EN, Öztaş G. Ev Kadınlarının Sosyal Görünüş Kaygıları ve Sağlıklı Yaşam Biçimi Davranışları. Hacettepe Spor Bilimleri Dergisi, 201728 (1), 11-23. 
17- Kılıç M, Karakuş Ö. Üniversite Öğrencilerinin Sosyal Görünüş Kaygıları İle Benlik Saygıları Ve Yalnızlık Düzeyleri Arasındaki İlişkinin İncelenmesi. Journal of Human Sciences, 2016 13(3): 3837-3852.

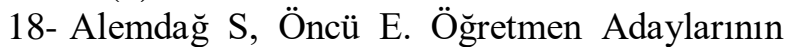
Fiziksel Aktiviteye Katılım ve Sosyal Görünüş Kaygilarının İncelenmesi, 20153.

19- Sanlier N, Pehlivan M, Sabuncular G, Bakan $\mathrm{S}$, Isguzar Y. Determining the relationship between body mass index, healthy lifestyle behaviors and social appearance anxiety. Ecol Food Nutr, 2018 57(2):124-139.

20- Telli E, Ünal Z. Üniversite öğrencilerinin sosyo-demografik özelliklerine göre sosyal görünüş kaygısı: bir alan araştırması. Mehmet Akif Ersoy Üniversitesi Sosyal Bilimler Enst Derg, 2016 8(15): 134-146.

21- Ülkü H. Sosyal görünüş kaygısı ile sosyal anksiyete arasındaki ilişkinin toplumsal cinsiyet bağlamında incelenmesi. Üsküdar Üniversitesi Sosyal Bilimler Enstitüsü Psikoloji Anabilim Dalı Klinik Psikoloji Bölümü, 2017.

22- Ben S. İstanbul'da yaşayan üniversite öğrencilerinin sosyal anksiyete düzeyleri ile beden algısı olumsuz değerlendirilme korkusu sosyal görünüş kaygısı arasındaki ilişkinin incelenmesi. Haliç Üniversitesi Sosyal Bilimler Enstitüsü Psikoloji Anabilim Dalı Uygulamalı Psikoloji (Tezli) Yüksek Lisans Program1, 2017.
23- Özcan H, Subaşı B, Budak B, Çelik M, Gürel ŞC, Yıldız M. Ergenlik ve Genç Yetişkinlik Dönemindeki Kadınlarda Benlik Saygıs1, Sosyal Görünüş Kaygıs1, Depresyon ve Anksiyete İlişkisi. JMOOD, 2013 3(3):107-13.

24- Sağlığın Teşviki ve Geliştirilmesine Yönelik Dönüm Noktaları (2011) http://sbu.saglik.gov.tr/Ekutuphane/kitaplar/sa $\% \mathrm{C} 4 \% 9 \mathrm{~F} 1 \% \mathrm{C} 4 \% \mathrm{~B} 1 \mathrm{~g} \% \mathrm{C} 4 \% \mathrm{~B} 1 \mathrm{n} \% 20 \mathrm{te} \% \mathrm{C} 5 \%$ 9Fviki.pdf. (Erişim tarihi: 02 Haziran 2017).

25- Türkiye Halk Sağlığı Kurumu, (2014). http://beslenme.gov.tr/index.php?lang= tr\&page $=346$. (Erişim tarihi: 02 Haziran 2017).

26- Titchener K, Wong QJ. A weighty issue: explaining the association between body mass index and appearance-based social anxiety. Eat Behav, 2015 16:13-6.

27- Koskina A, Van den Eynde F, Meisel S, Campbell IC, Schmidt U. Social appearance anxiety and bulimia nervosa. Eat Weight Disord, 2011 16(2):e142-5.

28- Brosof LC, Levinson CA. Social appearance anxiety and dietary restraint as mediators between perfectionism and binge eating: A six month three wave longitudinal study. Appetite. 2017 108:335-342.

29- Kavak F, Mankan T, Polat H, Ç Sarıtaş S, Sarıtaş S.Hemşirelerin manevi bakıma ilişkin görüşleri. İnönü Üniversitesi Sağlık Bilimleri Dergisi, 2014 3(1), 21-4. 